\title{
Distant Metastasis in Carcinoma Oral Cavity: Incidence and Prognostic Factors
}

\author{
Nikhil Kalyani ${ }^{1}$ Bharat Bhosale ${ }^{1,2,3}$ Shambhavi Singh ${ }^{3}$ Debayan Tarafdar ${ }^{3}$ Rakesh Katna ${ }^{1,2,3}$
}

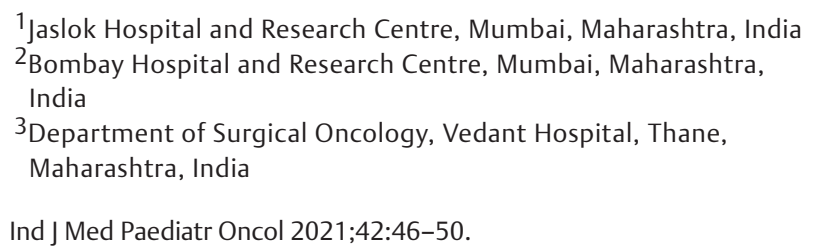

Address for correspondence Rakesh Katna, Department of Head Neck Surgical Oncology, Jaslok Hospital and Research Centre, Pedder Road, Mumbai 400026, Maharashtra, India (e-mail: katna.rakesh@gmail.com).

\begin{abstract}
Keywords

- carcinoma oral cavity

- differentiation

- distant metastasis

- nodal stage

$-\mathrm{PNI}$

Aim The predominant pattern of failure for oral carcinoma is locoregional failure. With improvement in locoregional control, incidence of distant metastasis has increased. Reported incidence of distant metastasis is 8 to $10 \%$. With an aim to define incidence and predictive factors for distant metastasis posttreatment of oral cavity cancer, the present analysis was done.

Materials and Methods This is a retrospective chart review of 531 patients who underwent surgery for oral cavity carcinoma from August 2013 to December 2017. All patients had undergone surgery followed by adjuvant treatment as per histopathology report.

Results The median age of the cohort was 49 years. The median follow-up of alive patients was 21 months (range: 1-56 months). Locoregional recurrence seen in 61, distant metastasis in 23, and 72 patients had locoregional recurrence with distant metastasis. Total incidence of distant metastasis was $18 \%$ (95 patients) with median detection 7 months' posttreatment. The sites of distant metastasis were: lung in 49 patients, bone in 9 patients, and multiple sites in 37 patients. Nodal stage (N2 and N3), differentiation, young age, and perineural invasion were associated with higher incidence of distant metastasis on multivariate analysis.

Conclusion The incidence of distant metastasis was found to be higher as compared with published literature. Possibility of adjuvant systemic therapy may be explored in future studies.
\end{abstract}

\section{Introduction}

Head and neck squamous cell carcinoma is one of the most common cancers worldwide. ${ }^{1}$ In the Indian population, it is the most common cancer in males and one of the three common cancers overall. ${ }^{2}$ Carcinoma oral cavity forms the majority of head neck squamous cell carcinoma in our group of patients. Large proportion of patients in our country present with locoregionally advanced disease. Optimal management of oral cavity cancer includes primary surgery followed by adjuvant treatment as per the histopathological report (radiotherapy with or without concurrent chemotherapy). The predominant failure pattern posttreatment is locoregional recurrence.

In the literature, incidence of distant metastasis of head and neck cancer has been reported at around 10\% ${ }^{3-5}$ There has been a gradual improvement in locoregional control posttreatment. At the same time, more patients are being diagnosed with distant metastasis from head and neck cancers. This increase in distant metastasis incidence off sets
DOI https://doi.org/ 10.1055/s-0041-1729512 ISSN 0971-5851
(C) 2021. Indian Society of Medical and Paediatric Oncology

This is an open access article published by Thieme under the terms of the Creative Commons Attribution-NonDerivative-NonCommercial-License, permitting copying and reproduction so long as the original work is given appropriate credit. Contents may not be used for commercial purposes, or adapted, remixed, transformed or built upon. (https://creativecommons.org/licenses/by-nc-nd/4.0/).

Thieme Medical and Scientific Publishers Pvt. Ltd. A-12, 2nd Floor, Sector 2, Noida-201301 UP, India 
any overall survival (OS) benefit for head and neck cancers from definitive locoregional treatment. This may be due to improved availability and use of positron emission tomography-computed tomography (PET-CT) and improvement in locoregional control.

With an aim to analyze incidence of distant metastasis and factors predicting distant metastasis for locally advanced squamous cell carcinoma (LAHNSCC), the present analysis was performed by our group.

\section{Materials and Methods}

The present study is chart review of maintained database of oral cavity cancer patients undergoing surgical treatment in our group. All oral cavity patients undergoing curative intent treatment were included in the analysis. The patients who had unresectable disease (post neoadjuvant chemotherapy [NACT]) or had distant metastasis at presentation were excluded from the analysis. Whole-body PET-CT scan or contrast-enhanced CT scan of thorax, abdomen, and pelvis was done for the diagnosis of distant metastasis for this group of patients.

The time frame of the study was from August 2013 to December 2017. All patients had histologically proven squamous cell carcinoma of the oral cavity. Distant metastatic workup was done for the patients who had a clinical suspicion of distant metastasis or multiple bulky nodes or nodes present in lower neck at baseline. Histopathological factors were documented for all patients. They received adjuvant radiotherapy/chemoradiotherapy based on their histopathology report after appropriate surgical resection.

Clinical follow-up was done every 3 months after completion of adjuvant radiation/chemoradiation. Clinical examination of oral cavity, larynx, and neck was done on follow-up. Radiological investigations were done when deemed necessary based on suspicion of recurrent disease. Recurrent disease was suspected if the patient presented with recurrent lesion in oral cavity, swelling in the neck nodal stations. Distant metastasis was suspected in patients with bone pain, chronic cough with or without hemoptysis, unexplained weight loss, and anorexia. Metastatic workup was done for patients with symptoms of distant metastasis and/or with surgically salvageable locoregional disease. PET-CT scan was done whenever feasible. No metastatic workup was done for patients who had nonsalvageable locoregional disease. Patients were followed up every 3 months till 2 years, every 6 months until 5 years and annually thereafter.

All statistical analysis was done using Statistical Package for the Social Sciences (SPSS 20, SPSS Inc., 233, Chicago, Illinois, United States) software. Survival analysis was done using Kaplan-Meier methods. Prognostic factors affecting the various disease end points were analyzed by log-rank test for univariate and cox proportional hazard method for multivariate analysis.

\section{Results}

Five hundred and thirty-one patients were enrolled in this analysis from August 2013 to December 2017. The median age of the cohort was 49 years (range: 17-71 years) with male predominance ( $\mathrm{M}: \mathrm{F}$ ratio of 5:1). Ninety-five percent of patients had a history of tobacco/smokeless tobacco consumption. Eighty-five percent of patients had locally advanced disease at the time of presentation. Two hundred and ninety patients (54\%) had pathological neck-node positive for metastasis, of which 184 patients (63\%) had multiple neck nodes. All demographic and histopathological parameters are shown in - Table 1.

Majority of the patients had microvascular reconstruction for the defect postsurgery. The microvascular reconstruction was done in 317 (66\%) patients while pedicle flaps in 121 (23\%) patients. Remaining patients had either primary closure or local flap.

NACT was given for 28 patients (5\%). Four hundred and sixty-two patients (87\%) received adjuvant radiotherapy. Concurrent chemotherapy was given in 220 patients. The median dose of radiation was $60 \mathrm{~Gy}$. Cisplatin was given weekly at $30 \mathrm{mg} / \mathrm{m}^{2}$ and the median number of concurrent chemotherapy cycles was 5 (range: 3-6).

At the time of analysis, 406 patients were alive with 374 patients without any evidence of disease. The median follow-up of alive patients was 21 months

Table 1 Baseline characteristics

\begin{tabular}{|l|l|}
\hline & Number of patients (\%) \\
\hline Age, median (range) & $49(17-71)$ \\
\hline Gender & \\
\hline Male:female & $452: 79$ \\
\hline Smoking habit & $35(6)$ \\
\hline Nonsmoker (\%) & $496(94)$ \\
\hline Smoker (\%) & \\
\hline Site & $317(60)$ \\
\hline Buccal mucosa/alveolus & $172(32)$ \\
\hline Tongue/FOM & $7(2)$ \\
\hline Lip & $29(6)$ \\
\hline Maxilla & \\
\hline Stage & $78(15)$ \\
\hline I, II & $453(85)$ \\
\hline III, IV & \\
\hline Reconstruction & $83(15)$ \\
\hline Primary closure & $10(2)$ \\
\hline Local flap & $121(23)$ \\
\hline PMMC & $317(60)$ \\
\hline Microvascular free flap & \\
\hline
\end{tabular}

Abbreviations: FOM, floor of mouth; PMMC, pectoralis major myocutaneous flap. 
(range: 1-56 months). Overall, 133 patients had locoregional recurrences.

Distant metastasis was seen in 95 patients (18\%). Of these 95 patients, 72 patients had locoregional failure along with distant metastasis. There were 10 patients with nonsalvageable local or regional recurrence for which metastatic workup was not done to document synchronous distant metastasis. These patients were not recorded as distant metastasis event for the present analysis. The most common site of distant metastasis was lung, followed by bone. Thirty-seven patients had a combination of lung/bone and skin nodules involvement ( $\mathbf{- T a b l e ~} 2$ ).

The overall distant metastasis-free survival for the cohort was $79 \%$ at 2 years and $75 \%$ at 3 years. The median time to develop distant metastasis was 7 months' (range: 1-34 months) postsurgery. Twenty-four patients had developed distant metastasis within 4 months' postsurgery. Median survival postdevelopment of distant metastasis was 2 months (range: 1-21 months).

On univariate analysis, multiple factors were significant for the development of distant metastasis.

However, on multivariate analysis, patients with high nodal burden ( $p=0.02)$ and perineural invasion (PNI) $(p=0.04)$,

Differentiation $(p=0.04)$, patients receiving NACT $(p=0.002)$, and age $<40$ years $(p=0.05)$ were significant factors for distant metastasis ( $\mathbf{- T a b l e ~} \mathbf{3}$ ).

\section{Discussion}

The incidence of distant metastasis in our group of patients is $18 \%$ with a 2 -year distant metastasis-free survival of $79 \%$.

Conventionally, head and neck cancers are being considered as locoregional disease. The predominant pattern of failure is locoregional recurrences. ${ }^{6,7}$ All treatment intensification has been traditionally targeted toward improvement in locoregional control. In spite of improved locoregional control, OS has been stagnant. One of the results of stagnant OS is higher incidence of distant metastasis. This rise is specially seen in the last couple of decades. ${ }^{8}$

Conventionally, the incidence of distant metastasis has been reported at around 8 to $13 \%{ }^{3-5,9,10}$ The reported incidence is higher for our group of patients. One of factors could

Table 2 Follow-up status

\begin{tabular}{|l|l|}
\hline Follow-up status & No of patients (\%) \\
\hline NED & $374(70)$ \\
\hline Primary recurrence & $4(1)$ \\
\hline Nodal recurrence & $1(0)$ \\
\hline Primary + nodal recurrence & $56(10)$ \\
\hline Distant metastasis & $23(4)$ \\
\hline $\begin{array}{l}\text { Locoregional recurrence + distant } \\
\text { metastasis }\end{array}$ & $72(14)$ \\
\hline Second primary & $1(0)$ \\
\hline
\end{tabular}

Abbreviation: NED, no evidence of disease.
Table 3 Prognostic factors (univariate analysis)

\begin{tabular}{|c|c|c|c|}
\hline & $\begin{array}{l}\text { Number of } \\
\text { patients }\end{array}$ & $\begin{array}{l}2 \text { years } \\
\text { DMFS (\%) }\end{array}$ & $\begin{array}{l}p \text {-Value } \\
\text { (Log rank) }\end{array}$ \\
\hline \multicolumn{4}{|l|}{ Sex } \\
\hline Male & 452 & 80 & 0.253 \\
\hline Female & 79 & 75 & \\
\hline \multicolumn{4}{|l|}{ Age } \\
\hline$<50$ & 280 & 83 & 0.189 \\
\hline$>50$ & 251 & 77 & \\
\hline \multicolumn{4}{|l|}{ NACT } \\
\hline Given & 28 & 54 & 0.001 \\
\hline Not given & 503 & 81 & \\
\hline \multicolumn{4}{|c|}{ Free microvascular flap } \\
\hline Yes & 317 & 81 & 0.271 \\
\hline No & 214 & 77 & \\
\hline \multicolumn{4}{|l|}{ T stage } \\
\hline $\mathrm{T} 1, \mathrm{~T} 2$ & 114 & 91 & 0.000 \\
\hline T3, T4 & 417 & 76 & \\
\hline \multicolumn{4}{|l|}{ Nodes } \\
\hline No, N1 & 347 & 89 & 0.001 \\
\hline N2, N3 & 184 & 62 & \\
\hline \multicolumn{4}{|l|}{ Nodes } \\
\hline Negative & 241 & 90 & 0.001 \\
\hline Positive & 290 & 70 & \\
\hline \multicolumn{4}{|l|}{ pT size $(\mathrm{cm})$} \\
\hline$<4$ & 384 & 84 & 0.01 \\
\hline$>4$ & 147 & 75 & \\
\hline \multicolumn{4}{|c|}{ Thickness (cm) } \\
\hline$<1$ & 216 & 87 & 0.01 \\
\hline$>1$ & 315 & 73 & \\
\hline \multicolumn{4}{|l|}{ Differentiation } \\
\hline Well & 53 & 94 & 0.002 \\
\hline Moderate & 384 & 81 & \\
\hline Poor & 93 & 65 & \\
\hline \multicolumn{4}{|l|}{ LV I } \\
\hline Absent & 425 & 81 & 0.05 \\
\hline Present & 106 & 72 & \\
\hline \multicolumn{4}{|l|}{ PNI } \\
\hline Absent & 291 & 84 & 0.001 \\
\hline Present & 240 & 73 & \\
\hline \multicolumn{4}{|l|}{ PNE } \\
\hline Absent & 330 & 86 & 0.001 \\
\hline Present & 201 & 69 & \\
\hline
\end{tabular}

(Continued) 
Table 3 (Continued)

\begin{tabular}{|c|l|l|l|}
\hline & $\begin{array}{l}\text { Number of } \\
\text { patients }\end{array}$ & $\begin{array}{l}\mathbf{2} \text { years } \\
\text { DMFS (\%) }\end{array}$ & $\begin{array}{l}p \text {-Value } \\
\text { (Log rank) }\end{array}$ \\
\hline Conc chemotherapy & & & \\
\hline Yes & 220 & 79 & 0.09 \\
\hline No & 311 & 82 & \\
\hline
\end{tabular}

Abbreviations: DMFS, distant metastasis-free survival; LV I, lymphovascular invasion; NACT, neoadjuvant chemotherapy; PNE, perinodal extension; $\mathrm{PNI}$, perineural invasion.

be higher proportion of gingivobuccal complex tumors in our series that has a better locoregional control as compared with tongue cancers. However, this was not significant on univariate analysis. ${ }^{11}$

The most common site of distant metastasis for head and neck cancers is reported to be lung and bone. ${ }^{12}$ Similar trend was seen in our analysis where lung was the most common site for distant metastasis followed by bone and skin nodules. We saw a higher distant metastasis in patients with higher node positive disease (N2, N3), PNI, and young patients. This is similar to reported literature except for perinodal extension. ${ }^{8}$

Distant metastasis predicts poor survival for head and neck cancer patients. The median OS after detection of distant metastasis in our study was 2 months (range: 1-21 months), as compared with 7 months reported by Wiegand et al postdistant metastasis survival depends on the general condition and fitness of patients. About one-fourth of patients are not able to receive any palliative chemotherapy postdistant metastasis.

High incidence of distant metastasis highlights the need for intense and effective systemic therapy. A meta-analysis has shown no significant benefit with either neoadjuvant or adjuvant chemotherapy for LAHNSCC. ${ }^{13}$ This option of adding systemic therapy needs to be explored further with alternate agents/schedules changing of agents and/or schedules. Over the last few years, the use of oral metronomic therapy has shown encouraging results for recurrent and/or unresectable head and neck cancers. ${ }^{14}$ Oral metronomic therapy is beneficial due to its convenience to use, lower cost, higher compliance, and favorable toxicity profile as compared with intravenous chemotherapy. The addition of oral metronomic therapy may be explored in future studies especially in high-risk group.

The most common chemotherapy schedule in concurrent setting is 3 weekly high-dose cisplatin in Western population. However, in Indian subcontinent, weekly cisplatin and $30 \mathrm{mg} / \mathrm{m}^{2}$ is practiced widely due to favorable toxicity profile. All patients in the present cohort had received weekly cisplatin. Recently, Noronha et al have shown that, weekly cisplatin is inferior in terms of oncological outcomes as compared with 3 weekly cisplatin. ${ }^{15}$ The cumulative dose of more than $200 \mathrm{mg} / \mathrm{m}^{2}$ may be needed for optimal outcomes. The incidence of systemic failures was similar in both arms.

As per the current guidelines, baseline metastatic workup is not routinely done for oral cavity carcinoma. The median time to development of distant metastasis in our study is
7 months with 24 patients developing metastasis within 4 months' posttreatment. This gives indirect evidence that these patients may be harboring distant metastasis at the time of locoregional treatment. We strongly recommend doing metastatic workup for LAHNSCC prior to any definitive locoregional treatment. This would prevent toxicity, morbidity, and cost related to locoregional treatments.

The strength of our analysis includes large series with good long-term follow-up. There are few limitations including retrospective analysis, use of weekly cisplatin and dose of $30 \mathrm{mg} / \mathrm{m}^{2}$ as concurrent chemotherapy.

\section{Conclusion}

The reported incidence of distant metastasis is higher in our series as compared with reported literature. A baseline metastatic workup may be routinely done for LAHNSCC patients. Future studies may be designed to explore effective systemic therapy that as of now remains as an unmet need.

\section{Financial Support and Sponsorship \\ Nil.}

\section{Conflicts of Interest}

There are no conflicts of interest.

\section{References}

1 Ferlay J, Soerjomataram I, Dikshit R, Eser S, Mathers C, Rebelo M. GLOBOCAN 2012: estimated cancer incidence, mortality and prevalence worldwide in 2012 v1.0, IARC Cancer Base No. 11. Int J Cancer 2015;136:E359-E386

2 Bray F, Ferlay J, Soerjomataram I, Siegel RL, Torre LA, Jemal A. Global cancer statistics 2018: GLOBOCAN estimates of incidence and mortality worldwide for 36 cancers in 185 countries. CA Cancer J Clin 2018;68(6):394-424

3 Marioni G, Blandamura S, Calgaro N, et al. Distant muscular (gluteus maximus muscle) metastasis from laryngeal squamous cell carcinoma. Acta Otolaryngol 2005;125(6):678-682

4 Bhandari V. Incidence of bone metastasis in carcinoma buccal mucosa. Indian J Med Paediatr Oncol 2016;37(2):70-73

5 Talmi YP, Cotlear D, Waller A, et al. Distant metastases in terminal head and neck cancer patients. J Laryngol Otol 1997;111(5):454-458

6 Bernier J, Domenge C, Ozsahin M, et al. European Organization for Research and Treatment of Cancer Trial 22931. Postoperative irradiation with or without concomitant chemotherapy for locally advanced head and neck cancer. N Engl J Med 2004;350(19):1945-1952

7 Cooper JS, Pajak TF, Forastiere AA, et al; Radiation Therapy Oncology Group 9501/Intergroup. Postoperative concurrent radiotherapy and chemotherapy for high-risk squamous-cell carcinoma of the head and neck. N Engl J Med 2004;350(19):1937-1944

8 Sumioka S, Sawai NY, Kishino M, Ishihama K, Minami M, Okura M. Risk factors for distant metastasis in squamous cell carcinoma of the oral cavity. J Oral Maxillofac Surg 2013;71(7):1291-1297

9 Holsinger F, Dong W, Bekele N, Weber R, Kies M, Glisson B. Clinicopathological predictor of distant metastasis in head and neck cancers. J Clin Oncol 2009;27(15(Suppl):6086

10 Duprez F, Berwouts D, De Neve W, et al. Distant metastases in head and neck cancer. Head Neck 2017;39(9):1733-1743 
50 Distant Metastasis in Carcinoma Oral Cavity Kalyani et al.

11 Listl S, Jansen L, Stenzinger A, et al. GEKID Cancer Survival Working Group. Survival of patients with oral cavity cancer in Germany. PLoS One 2013;8(1):e53415

12 Wiegand S, Zimmermann A, Wilhelm T, Werner JA. Survival after distant metastasis in head and neck cancer. Anticancer Res 2015;35(10):5499-5502

13 Pignon JP, le Maître A, Maillard E, Bourhis J; MACH-NC Collaborative Group. Meta-analysis of chemotherapy in head and neck cancer (MACH-NC): an update on 93 randomised trials and 17,346 patients. Radiother Oncol 2009;92(1):4-14
14 Patil VM, Noronha V, Joshi A, et al. Comparison of paclitaxel-cetuximab chemotherapy versus metronomic chemotherapy consisting of methotrexate and celecoxib as palliative chemotherapy in head and neck cancers. Indian J Cancer 2017;54(1):20-24

15 Noronha V, Joshi A, Patil VM, et al. Once-a-week versus onceevery-3-weeks cisplatin chemoradiation for locally advanced head and neck cancer: a phase III randomized noninferiority trial. J Clin Oncol 2018;36(11):1064-1072 